\title{
Políticas públicas e relações federativas: o Sistema Nacional de Cultura como arranjo institucional de coordenação e cooperação intergovernamental ${ }^{1}$
}

Adélia Zimbrão

\section{Sobre o que se versa?}

Entre as questões conformadoras da complexidade que atravessa o processo de materialização dos direitos sociais, identificam-se débeis acordos entre os entes federados no tocante à provisão de políticas públicas nacionais. Fragilidade que persiste ao longo desses últimos vinte e quatro anos, apesar de o federalismo tripartite consagrado no Texto Constitucional ser considerado de tipo cooperativo ${ }^{2}$, como ilustra o art. 23 da Carta Magna de 1988 e seu parágrafo único, que tratam das competências comuns a todas as esferas da Federação e da cooperação entre elas para o “(...) equilíbrio do desenvolvimento e bem-estar em âmbito nacional” (Parágrafo único, art. 23, CF/1988). No entanto, o compartilhamento de poder e autoridade entre governo central e governos subnacionais sobre a ação estatal não é "automático" e nem pacífico. A Federação brasileira "desliza" num contínuo entre relações de competição e de cooperação, em que há projetos políticos frequentemente divergentes e em disputa. 
Essa configuração federativa gera tensões e dilemas ao Estado, na sua obrigação de garantir direitos que requerem políticas públicas para serem gozados. Nesse sentido, tendo como diretriz constitucional a universalização das denominadas políticas sociais, um dos grandes desafios a ser enfrentado pela União diz respeito às relações intergovernamentais. Não obstante esse cenário, a colaboração interfederativa tem sido experimentada em algumas áreas, como, entre outras, as da saúde (Sistema Único de Saúde - SUS) e da assistência social (Sistema Único de Assistência Social - SUAS), por meio da constituição de arranjos político-institucionais que visam a promover a convergência de esforços da União, Distrito Federal, Estados e Municípios e superar pontos de estrangulamento concernentes ao desenvolvimento de políticas públicas. Os mecanismos - que podem ser considerados inovadores ao observarmos o contexto - de coordenação e cooperação intergovernamental, adotados pelas citadas áreas, objetivam, em especial, conciliar as tensões federativas - resultantes principalmente das significativas desigualdades sociais e regionais do País - de modo a possibilitar o cumprimento das obrigações constitucionais pelos entes federados, referentes às responsabilidades e propósitos comuns. Assim, a descentralização de responsabilidades para os poderes executivos subnacionais, na condução de políticas sociais, ocorre com base nas políticas públicas nacionais, acordadas nas instâncias apropriadas, previstas na configuração institucional dos sistemas de políticas públicas de saúde e de assistência social.

No que diz respeito às políticas culturais, estas também não escapam da problemática atinente às relações federativas. $\mathrm{O}$ Ministério da Cultura, na última década, vem conduzindo um processo de reformulação e redimensionamento de suas políticas, inclusas nesse cenário a criação e estruturação do Sistema Nacional de Cultura ${ }^{3}$ (SNC), que aspira a ser o principal mecanismo de articulação e coordenação federativa para implementação de programas e ações culturais.

O trabalho aqui apresentado tem o objetivo de analisar a proposta do Sistema Nacional de Cultura a partir da conceituação política regulada e não regulada, elaborada pela cientista política Marta Arretche para distinguir relações intergovernamentais relativas à autoridade sobre a formulação e sobre a execução de políticas públicas. Balizado pelas questões concernentes às relações federativas e à descentralização de políticas públicas, o estudo examina a configuração institucional de articulação e compartilhamento interfederativo de políticas públicas de cultura presente no projeto do sistema, tomando como referência o Sistema Único de Saúde, por ser o modelo inspirador de tal iniciativa.

O Sistema Nacional de Cultura visa a colaborar com o aprimoramento do pacto federativo ao estabelecer parâmetros para a ação cooperativa, com cofinanciamento, entre os diversos níveis de governo, na área de cultura. O desafio posto ao Estado - acentuado por um contexto de desigualdades inter e intraestaduais - consiste em assegurar o exercício dos direitos culturais ${ }^{4}$ a todo cidadão, equilibrando as ações públicas necessárias para o cumprimento de tal obrigação, com o singular desenho federativo tripartite brasileiro. Nesse sentido, o que está em debate são os meios para garantir o direito à nominada "cidadania cultural", combater as desigualdades territoriais e assegurar a diversidade cultural, assim como a construção de canais para o indispensável diálogo federativo. 
A garantia do exercício dos direitos culturais a todos os brasileiros é competência constitucional comum às três esferas de governo. As informações disponíveis sobre este tema revelam que há variações territoriais em relação ao acesso dos cidadãos aos bens culturais e às políticas públicas de cultura. Há uma expressiva concentração de recursos públicos e ações culturais nas maiores capitais dos estados da Região Sudeste. Além disso, um significativo percentual da população está excluído dos benefícios assegurados por essas políticas (Cultura em Números Anuário de Estatísticas Culturais - 2009).

O Suplemento de Cultura da Pesquisa de Informações Básicas Municipais (Munic, 2006), do Instituto Brasileiro de Geografia e Estatística (IBGE), que levantou um conjunto de informações a respeito da diversidade cultural e territorial dos municípios brasileiros, confirmou a percepção já existente a respeito da baixa centralidade das políticas culturais na agenda dos governos locais ${ }^{5}$, além de mostrar a pouca institucionalização do setor da cultura nos municípios e a precária capacidade organizacional e administrativa do poder executivo local. Em outros termos, grande parte dos governos subnacionais municipais não dá a devida atenção à área da cultura. Em decorrência, esses entes federados não desenvolvem políticas culturais, mas apenas ações muito pontuais. O entendimento mais comum por parte das autoridades competentes é ofertar "entretenimento" à população local.

$\mathrm{Na}$ outra ponta, no âmbito federal, na última década, várias iniciativas foram tomadas. Porém o alcance das ações do Ministério da Cultura é limitado, dado o tamanho do País, as diversidades de várias ordens (cultural, geográfica, ambiental etc.) e as condições restritas de gestão e de recursos do próprio órgão. Portanto, argumenta-se que a redefinição induzida de responsabilidades por meio da descentralização pactuada de políticas públicas de cultura é essencial para fortalecer a função do Estado em assegurar o pleno exercício dos direitos culturais, ainda mais num país com a dimensão territorial do Brasil e expressiva diversidade cultural. Nesse sentido, os mecanismos institucionais previstos/desenhados para forjar a atuação

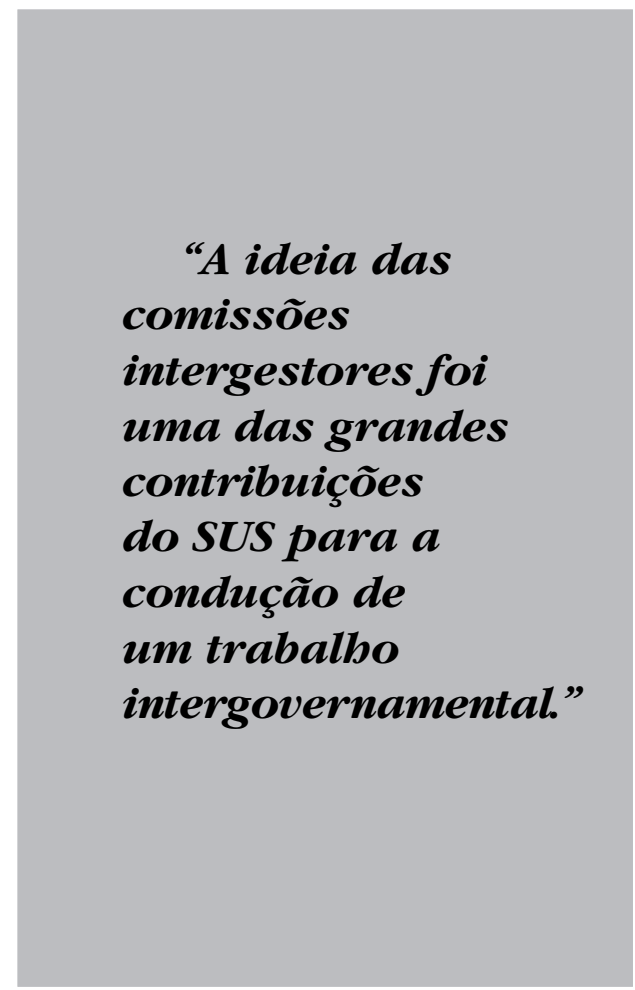

estatal de forma articulada e cooperativa estariam na proposta do Sistema Nacional de Cultura.

Relações federativas, políticas públicas e regulação federal

Várias questões perpassam a discussão sobre o federalismo e os efeitos de seu 
desenho para as relações federativas: competição, cooperação, autonomia política das unidades subnacionais, ingerência/ intromissão/interferência federal, reforma tributária, pacto federativo, entre outros aspectos. Essas questões alimentam um intenso debate teórico a respeito da pertinência do modelo de federalismo brasileiro.

O federalismo, conforme Souza (2005), tem sido associado mais à descentralização, em muitos trabalhos no país, principalmente após a Constituição de 1988, do que a uma ordem política e constitucional com suas particularidades. A autora aponta ainda que é significativa a presença de textos que analisam as relações que se estabelecem entre esferas de governos tendo como foco as designadas relações intergovernamentais. Esse interesse também seria “(...) resultado da emergência de políticas descentralizadas, mas, sobretudo, pelo considerável aumento de programas 'intergovernamentalizados', tendência observada na maioria dos países federais e unitários" (SouzA, 2005, p. 106).

Da perspectiva das relações intergovernamentais, para Almeida (2005), a Federação brasileira pode ser entendida como uma configuração complexa na qual convivem tendências centralizadoras e descentralizadoras, estimuladas por múltiplos fatores, gerando efeitos diversos ao longo do território nacional. A seu ver, o modelo cooperativo adotado constitucionalmente em 1988 para o federalismo brasileiro “(...) combinou a manutenção de áreas próprias de decisão autônoma das instâncias subnacionais; descentralização no sentido forte de transferência de autonomia decisória e de recursos para os governos subnacionais e a transferência para outras esferas de governo de responsabilidades pela implementação e gestão de políticas e programas definidos no nível federal'
(Almeida, 2005, p. 32, grifo nosso). Desse modo, para a autora, a apreciação dos caminhos do federalismo brasileiro, no que diz respeito à polaridade descentralizaçãorecentralização, “(...) deve levar em conta a complexidade desse arranjo cooperativo e as formas distintas que assumem as relações governamentais em diferentes áreas de políticas públicas" (Almeida, 2005, p. 32).

Abrucio (2005), com a intenção de ir além da dicotomia centralização versus descentralização, propõe a temática da coordenação federativa como objeto de exame. Em seu texto, comenta a respeito de um estudo realizado pela Organization for the Economic Cooperation and Development (OECD), com base em diversas federações, que aborda a questão centralização e descentralização, e no qual é apresentada a conclusão de que "Nós precisamos agora estar dispostos a mover em ambas as direções - descentralizando algumas funções e ao mesmo tempo centralizando outras responsabilidades cruciais na formulação de políticas. Tais mudanças estão a caminho em todos os países" (OECD, 1997, p. 13 apud Aвrucio, 2005, p. 42, grifo nosso). A seu ver, há dilemas de coordenação intergovernamental constatados internacionalmente, que o Brasil igualmente precisa enfrentar. Por isso, considera necessário analisar o problema da coordenação interfederativa, que compreende as formas de integração, compartilhamento e decisão conjunta existentes nas federações.

Entretanto, o caminho analítico trilhado por Abrucio (2005) difere do percorrido neste trabalho, posto que, como dispõe a própria OECD, às vezes é necessário centralizar outras responsabilidades cruciais na formulação de políticas. Essa perspectiva diverge das questões trabalhadas por Abrucio (2005), que destaca como aspecto inovador 
do sistema de Federação, no que tange à organização político territorial do poder, o compartilhamento matricial da soberania em contraposição ao piramidal.

Assim, a tensão entre autonomia político-institucional federativa e regulação federal vem se traduzindo em complexos processos de descentralização e centralização dos poderes governamentais entre as unidades jurisdicionais. Nesse sentido, não se pretendeu esgotar o assunto, pois, tal como destaca Almeida, "a relação entre federalismo e descentralização, em termos conceituais e empíricos, está longe de ser simples e incontroversa" (2005, p. 30).

Para Lima et al. (2012), problemas como as desigualdades territoriais, que são de ordem estrutural, dificilmente podem ser resolvidos apenas pela ação articulada dos estados e municípios, sem uma efetiva atuação do governo federal.

Ainda numa outra perspectiva, diferente dos autores que focalizam principalmente a autonomia dos governos subnacionais, Arretche (2010) vai trabalhar com a ideia de que é possível compatibilizar descentralização da execução de políticas com a centralização da autoridade, mesmo em estados federativos. É essa autoridade do poder central de definir políticas e programas que mune o governo federal de instrumentos para coordenar políticas públicas.

Para Marta Arretche - que tem entre sua produção acadêmica a investigação de temas como descentralização de políticas públicas, políticas sociais, relações federativas e federalismo -, os teóricos, que questionam o atual modelo federativo do Estado brasileiro, têm tido como principais objetos de análise a autonomia dos governos subnacionais e as regras eleitorais. Nesse sentido, conforme assinala Arretche (2010), características presentes no Estado e no sistema político brasileiro ganham demasiado realce nas interpretações desses estudiosos. Porém, essa pesquisadora considera que há um superdimensionamento na importância desses traços, por ignorarem dois aspectos que julga como centrais: "o papel das desigualdades regionais na escolha da fórmula federativa adotada no Brasil, bem como a importância das relações entre a União e os governos subnacionais sobre seu funcionamento" (2010, p. 588). Por isso, para uma interpretação mais precisa a respeito das motivações para a adoção da fórmula federativa no Brasil e de seus resultados, Arretche considera necessário incluir na análise as dimensões desigualdades territoriais e relações federativas central-local.

Como bem observa Arretche (2010), a nação brasileira é historicamente dividida entre jurisdições ricas e pobres e essa clivagem está na origem da escolha por um desenho de Estado e de suas instituições políticas que pudesse proporcionar o equilíbrio regional. Portanto, para tal finalidade, segundo a autora, concentrou-se autoridade decisória no governo central, no processo de construção do Estado-nacional brasileiro, bem como no poder regulatório e de gasto, prevalecendo, dessa forma, a ideia de uma "comunidade nacional única" sobre os pleitos por autonomia regional. Assim, as transferências de recursos federais têm sido, historicamente, como assinala Arretche, um componente central na constituição desse Estado, na busca de reduzir desigualdades territoriais sócio-econômicas.

No que se refere às relações federativas central-local, segundo Arretche (2010), as prioridades políticas dos governos estaduais e municipais podem ser amplamente afetadas pelos mecanismos de incentivos decorrentes de suas interações com níveis superiores de governo, tal como já expuseram pesquisadores desse tema (SELLERS, Jefferey M. e Lidström, Anders, 2007; e 
RaziN, Eran, 2007). Além disso, Arretche destaca que, mesmo em estados federativos, é possível compatibilizar descentralização da execução de políticas com a centralização da autoridade (OBINGER, Herbert; LeIBFrIED, Stephan; e CASTLES, Francis G., 2005). Assim, de acordo com sua reflexão, é preciso diferenciar a dimensão de autoridade sobre a formulação de políticas públicas, da dimensão de autoridade sobre a execução de políticas públicas, para uma análise mais apropriada dessas relações. Sua argumentação prossegue:

"Distinguir quem formula de quem executa permite inferir que, no caso brasileiro, embora os governos subnacionais tenham um papel importante e até mesmo pouco usual em termos comparados - no gasto público e na provisão de serviços públicos, suas decisões de arrecadação tributária, alocação de gasto e execução de políticas públicas são largamente afetadas pela regulação federal.” (Arretche, 2010, p. 589).

Em outros termos, a agenda dos governos estaduais e municipais é "balizada" por normas e supervisão federais, mesmo se tratando de unidades politicamente autônomas, com responsabilidade na arrecadação de tributos e na execução de políticas, pois suas decisões são limitadas por legislação nacional (ARRETCHE, 2010).

Portanto, para estudar o fenômeno federalismo brasileiro, Arretche (2010) considera essencial examinar o impacto da regulação federal sobre as decisões dos governos locais, assim como sobre as desigualdades sócio-regionais, que acarretam discrepâncias de acesso dos cidadãos a políticas públicas no cenário nacional.

A tradição de centralização da autoridade política, por conseguinte, de regulação federal - presente no Estado federativo brasileiro - para implementar políticas de compensação das desigualdades sociais e territoriais tem, entre sua fundamentação, como expõe Arretche (2010), a desconfiança na disposição das elites políticas locais em prover serviços públicos básicos e respeitar os direitos dos cidadãos. Por isso, conforme Arretche, "a regulação federal parece ser uma condição para 'amarrar' subunidades independentes em torno de um dado objetivo nacional" (2010, p. 611).

Portanto, para Arretche (2010), a legitimidade da regulação federal, ou seja, de que a União deve estar munida de aparato para legislar e supervisionar a ação dos governos subnacionais apoia-se tanto na ideia de nação, de pertencimento a uma comunidade nacional única, quanto no receio e suspeita com relação às práticas dos governantes locais. Desse modo, estados federativos que concentram na União autoridade regulatória, segundo Arretche, têm a possibilidade de constituir mecanismos institucionais para atuarem na direção da diminuição das desigualdades.

Assim, o sentido que Arretche (2010) atribui à regulação federal diz respeito ao conjunto da legislação federal sobre as políticas executadas pelas unidades constituintes, à autoridade para supervisionar essas políticas e à função de redistribuição de recursos entre os entes federados, isto é, refere-se à regulamentação e à supervisão federais sobre as políticas operacionalizadas pelos governos estaduais e municipais. "É, portanto, o emprego dos recursos institucionais da União para regular a execução descentralizada de uma dada política que a converte em uma política regulada" (2010, p. 604). Nesse sentido, para Arretche, essa possibilidade existe potencialmente para qualquer área de política pública, em razão das propriedades do federalismo brasileiro. 
Com base na reflexão apresentada, Arretche (2010), no que se refere às políticas descentralizadas, observa que é possível distinguir dois tipos atinentes à relação central-local:

(1) reguladas: aquelas nas quais a legislação e a supervisão federais limitam a autonomia decisória dos governos subnacionais, estabelecendo patamares de gasto e modalidades de execução das políticas.

(2) não reguladas: aquelas nas quais a execução das políticas (policy-making) está associada à autonomia para tomar decisões (policy decision-making) (2010, p. 603).

Arretche (2010) explica que um elemento fundamental das políticas federais de regulação referentes às políticas descentralizadas são as normas que vinculam as receitas dos governos subnacionais ao gasto em políticas específicas. Como consequência, a autonomia decisória desses entes federados, no que tange à alocação de seus próprios recursos, fica limitada. Entretanto, Arretche observa que, de qualquer forma, o governante local possui autoridade sobre a execução, dentro das regras de uso dos recursos. Ademais, sua autonomia política lhe permite a possibilidade da discordância.

A partir de sua tipologia, Arretche (2010) analisou comparativamente as políticas públicas de educação e saúde, classificadas como reguladas, e as políticas das áreas de desenvolvimento urbano (infraestrutura urbana, habitação e transporte público), consideradas como não reguladas. No Estado brasileiro, esses serviços básicos ficam a cargo dos governos municipais. A investigação, de acordo com Arretche, consistiu em identificar os efeitos das relações central-local sobre a desigualdade na oferta de serviços municipais, por meio do exame da provisão de serviços públicos e a alocação setorial do gasto.

Os resultados encontrados, segundo Arretche (2010), demonstram primazia no gasto em saúde e em educação, e grande desigualdade na prioridade de alocação de recursos financeiros às políticas de infraestrutura urbana, ou seja, políticas reguladas e não reguladas apresentam

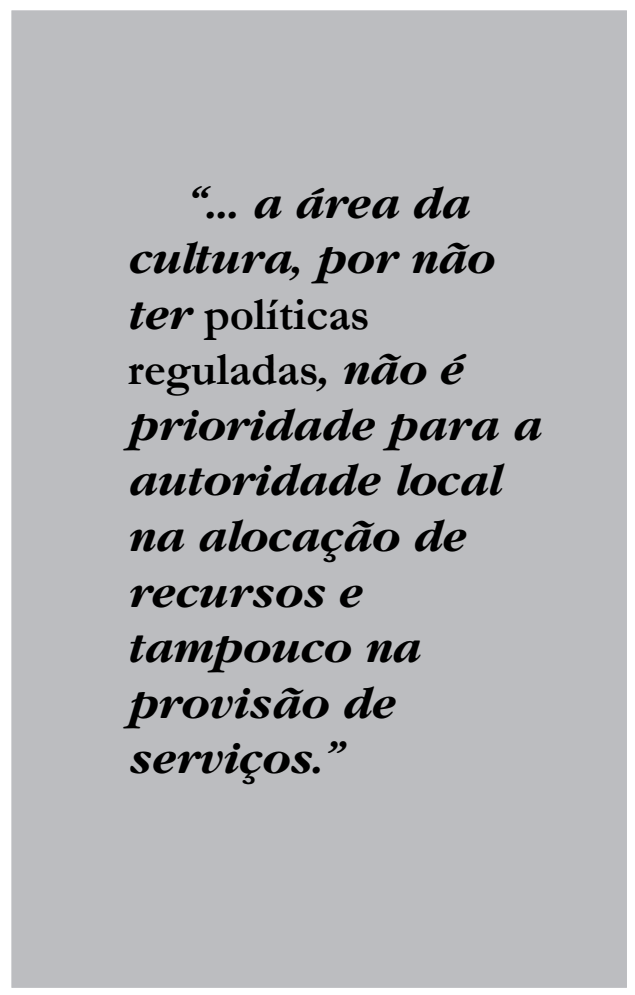

comportamentos distintos. Arretche observou que a desigualdade entre municípios, referente ao gasto nas políticas reguladas, é consideravelmente menor do que nas políticas não reguladas. Conforme suas considerações, o impacto da regulação federal sobre as decisões dos governos locais fica claramente demonstrado no padrão de gasto apurado dos municípios 
brasileiros: "alta prioridade e baixa desigualdade nas políticas reguladas acompanhado de baixa prioridade e elevada desigualdade nas políticas não reguladas" (2010, p. 611). Em outras palavras, as políticas reguladas têm precedência na alocação do gasto municipal, enquanto que as políticas não reguladas não têm preferência de gasto. Logo, para Arretche (2010), é o papel de regulamentação e de supervisão exercido pela União que pode explicar esse comportamento convergente dos municípios, em que há redução do intervalo de desigualdades, no que tange à provisão de serviços e aplicação de recursos em saúde e educação.

O que se evidencia, portanto, segundo Arretche (2010), é que há uma tensão entre a redução das desigualdades territoriais de capacidade de gasto e de provisão de serviços públicos e a plena autonomia decisória dos governos locais. O exercício dessa autonomia pela autoridade local possibilita a discordância política, que pode produzir divergências de políticas públicas entre jurisdições. Projetos políticos muito distintos e até opostos, em conjunto com limites de capacidade de recursos das prefeituras, levam a grandes variações nas prioridades municipais de gasto. Desse modo, a propensão é o aumento da desigualdade intermunicipal no fornecimento de serviços públicos. Entretanto, conforme a autora, estados federativos que conciliam regulação centralizada e autonomia política dos governos municipais tendem a restringir os patamares da desigualdade territorial, pois “a combinação de regulação das receitas municipais com regulação das despesas municipais tem como efeito mais uniformidade de gasto nas políticas reguladas" (2010, p. 610). Assim, é por meio de mecanismos institucionais regulatórios e redistributivos, como vinculação de receitas municipais, transferências de recursos federais e transferências condicionadas universais, que a União atua na diminuição de desigualdades interjurisdicionais de receita e na redução de desigualdades territoriais de acesso dos cidadãos brasileiros a políticas públicas.

Outro aspecto importante observado por Arretche (2010), acerca das políticas reguladas analisadas, é que os repasses de recursos não estão associados a barganhas políticas, ao contrário, são feitos com base em critérios públicos e universais, regulados por regras constitucionais ou infraconstitucionais.

A citação abaixo pode ser considerada uma espécie de síntese de suas considerações:

"Portanto, em estados federativos que centralizem a formulação de políticas executadas pelas unidades constituintes e que contam com um sistema interjurisdicional de transferências, é possível encontrar redução das desigualdades territoriais. Assim, de acordo com esta teoria, os papéis regulatório e redistributivo do governo central seriam mecanismos necessários para obter cooperação entre jurisdições". (Arretche, 2010, p. 593).

Posto que, conforme Arretche, "não há nenhuma garantia intrínseca à autonomia dos governos locais que os torne responsáveis, comprometidos com as necessidades dos cidadãos e determinados a administrar com eficiência" (2004, p. 334), as atribuições de regulação e de redistribuição do governo central seriam dispositivos inevitáveis para obter cooperação entre jurisdições e adesão dos governos subnacionais às políticas públicas, em especial às sociais (ARretche, 2010). 
Assim, a baixa centralidade das políticas sociais na agenda dos governos locais que, por consequência da inação, contribui para a manutenção da desigualdade vem sendo enfrentada justamente por meio de aparatos institucionais de incentivos e controles, que estimulam e também forjam o comprometimento desses dirigentes com determinadas políticas.

Estrutura e mecanismos de coordenação e cooperação federativa inovadores: o SUS

A regulação federal da saúde - apontada por Arretche (2010) como possível fator de redução da desigualdade entre municípios na provisão de serviços públicos nessa área - tem se realizado nas últimas duas décadas pelo Sistema Único de Saúde (SUS). O SUS, definido constitucionalmente pelos princípios de universalidade, equidade, integralidade, controle social e descentralização (Art. 196 a 200 da Constituição brasileira de 1988), foi complementado por normas infraconstitucionais, como as Leis Orgânicas da Saúde, Lei no 8080 - que regula as condições para a promoção, proteção e recuperação da saúde, a organização e o funcionamento das ações e serviços de saúde - e Lei no 8142 - que dispõe sobre a participação da comunidade na sua gestão, sobre as transferências intergovernamentais e vincula descentralização à municipalização -, ambas de 1990, mas que passaram por alterações e ajustes posteriores. Além desses suportes jurídicos de regulamentação da política de saúde, há vários outros instrumentos normativos que, ao longo desses vinte e dois anos, foram sendo editados de acordo com as circunstâncias político-institucionais, com as condições das interações federativas e com os processos necessários para a estruturação do sistema.

O SUS é, desse modo, um sistema de descentralização político-administrativa de responsabilidades na condução das ações públicas de saúde, integrado pelos governos nacional e subnacionais, com organização regionalizada e hierarquizada da rede de serviços, com direção única em cada esfera governamental e com participação social em seu comando. É também um modelo de planejamento e gestão de políticas públicas que buscou promover a racionalização dos serviços de saúde por meio da integração das redes federal, estadual e municipal, do redesenho do papel e atribuições de cada ente federado, da definição de fontes de financiamento e da criação de mecanismos automáticos de transferência de recursos no interior da rede pública e privada.

O SUS, de acordo com Arretche (2004), construiu, entre 1988 e 1993, uma complexa estrutura institucional para a tomada de decisões. Nesse sentido, fazem parte de sua configuração instâncias de articulação, pactuação e deliberação de políticas públicas. As conferências e os conselhos (de composição paritária) são arenas políticas (reproduzidas nos três níveis federativos) de negociação entre governo e sociedade civil, para deliberações das ações de saúde e de seu planejamento, além de serem instâncias de controle social. As Comissões Intergestores Tripartite (entre União, Estados e Municípios) e Bipartite (entre Estado e Municípios) são espaços institucionalizados de cogestão, onde ocorrem as negociações e os acordos entre os níveis de governo, referentes à operacionalização do SUS (gerenciamento e financiamento). Ademais, o SUS tem entre seus principais instrumentos de gestão planos de saúde e fundos de recursos do setor, 
todos relativos às esferas nacional, estadual e municipal.

Nesse sentido, o desafio de coordenação no SUS, no que diz respeito às relações federativas, foi enfrentado por meio da repartição de competências e atribuições entre as unidades federativas de governo. $\mathrm{Na}$ distribuição das responsabilidades, a União é a encarregada das funções de formulação da política nacional de saúde, financiamento e coordenação das ações intergovernamentais. É incumbência também da instância federal, em seu âmbito de atuação, monitorar, avaliar, capacitar e sistematizar as informações. Cabem aos estados, ao Distrito Federal e aos municípios, respeitando os princípios e as diretrizes estabelecidos pela política nacional de saúde, a coordenação e a execução dos programas e ações do setor, dentro de suas respectivas esferas de competência, além do cofinanciamento. Os governos subnacionais participam do processo de formulação da política de saúde por terem representações nas arenas de articulação, pactuação e deliberação. Em tese, esses espaços de negociação institucionalizados buscam suprimir do governo federal a possibilidade de estabelecer unilateralmente as regras de funcionamento do SUS, posto que atuariam como um mecanismo de contrapeso à concentração de autoridade conferida ao Executivo federal (ARretche, 2004).

O Ministério da Saúde, ao longo da década de 1990 e meados dos anos 2000, no processo de construção do SUS, editou sucessivas normas operacionais que tinham como objetivo definir os vários aspectos relativos à organização e forma de funcionamento do sistema, como arenas decisórias, fluxos de financiamento e estruturação do modelo de atenção à saúde. Nesse sentido, para induzir e regular a descentralização, foram implementadas as Normas
Operacionais Básicas do SUS - NOB/91, $\mathrm{NOB} / 93$ e NOB/96 -, que provocaram a redefinição de atribuições e competências das esferas de governo (federal, estadual e municipal) no que tange à gestão, organização e prestação de serviços de saúde, por meio da transferência de recursos (principalmente financeiros) do nível federal e estadual para os municípios. Já as Normas Operacionais da Assistência à Saúde NOAS/2001 e NOAS/2002 - tiveram um papel de estimular a regionalização da assistência à saúde por meio da organização de redes de serviços que articulassem os vários níveis de atenção, centralizando nas secretarias estaduais de saúde a função de organizar os sistemas microrregionais de saúde.

Em suma, esses instrumentos de regulação tiveram por finalidade disciplinar a descentralização, o financiamento e a relação entre os três níveis de governo, instituindo mecanismos de coordenação e cooperação interfederativa e de indução à adesão dos governos locais à política de saúde. Além disso, outro propósito da edição dessas regras organizacionais foi normatizar a gestão pública da política de saúde no território brasileiro, a ser exercida de modo sistêmico pelos entes federados.

Com a mudança de governo em 2003, que resultou na entrada de novos dirigentes no Ministério da Saúde, conforme Paim e Teixeira (2007), instalou-se um debate sobre a alternativa excessivamente "normativa" tomada durante a década de 1990. Uma crítica feita, segundo Lima (2012), foi a de que esse modelo de descentralização - de intensa normatização vinculada aos incentivos financeiros - conduzido no SUS pelo governo federal teria provocado "burocratização das relações intergovernamentais" e "fragmentação acentuada dos mecanismos de transferência de recursos federais” (2012, 
p. 1905). Por isso, estabeleceu-se o diagnóstico de que seriam indispensáveis alterações nas formas de relacionamento entre as esferas de governo, no tocante à política de saúde.

Esse processo de discussão culminou na aprovação, em 2006, pelo Conselho Nacional de Saúde e pela Comissão Intergestores Tripartite, do Pacto pela Saúde ${ }^{6}$. Os pactos representariam novas práticas, em substituição aos métodos e ferramentas adotados até aquele momento, por serem compreendidos como novo instrumento de política, para instituir um processo de negociação permanente entre gestores, em busca da superação dos conflitos intergovernamentais, com o propósito de garantir a implementação de políticas e ações prioritárias. Nesse sentido, a inovação mais significativa refere-se à pactuação como mecanismo de gestão, de coordenação interfederativa da política de saúde.

O Ministério da Saúde, portanto, com esse novo mecanismo, segundo Paim e Teixeira (2007), busca substituir a estratégia adotada anteriormente, “(...) a de induzir a tomada de decisões no âmbito estadual e municipal a partir de incentivos financeiros, por uma outra centrada no compromisso político entre os gestores (...)" (Paim e Teixeira, 2007, p. 1822). Nesse sentido, o espaço próprio para a construção desses acordos políticos intergovernamentais, no âmbito nacional, é a Comissão Intergestores Tripartite, e, em cada estado, são as Comissões Intergestores Bipartites.

Pode-se dizer que, mesmo com a mudança de estratégia, que busca comprometer politicamente os gestores, por meio de maior participação na tomada de decisão, é o governo federal quem controla o financiamento e os mecanismos de coordenação intergovernamental.
Sabe-se que o SUS enfrenta muitos desafios e que, mesmo após duas décadas de implementação, sua configuração institucional encontra-se ainda em processo de adequação no País. Há uma vasta literatura crítica que analisa tanto a organização, funcionamento e gestão do sistema quanto seus aspectos político-institucionais, e que aponta problemas de várias ordens, mas nenhuma aborda a ideia de desmontagem do sistema. Com todos os percalços, os

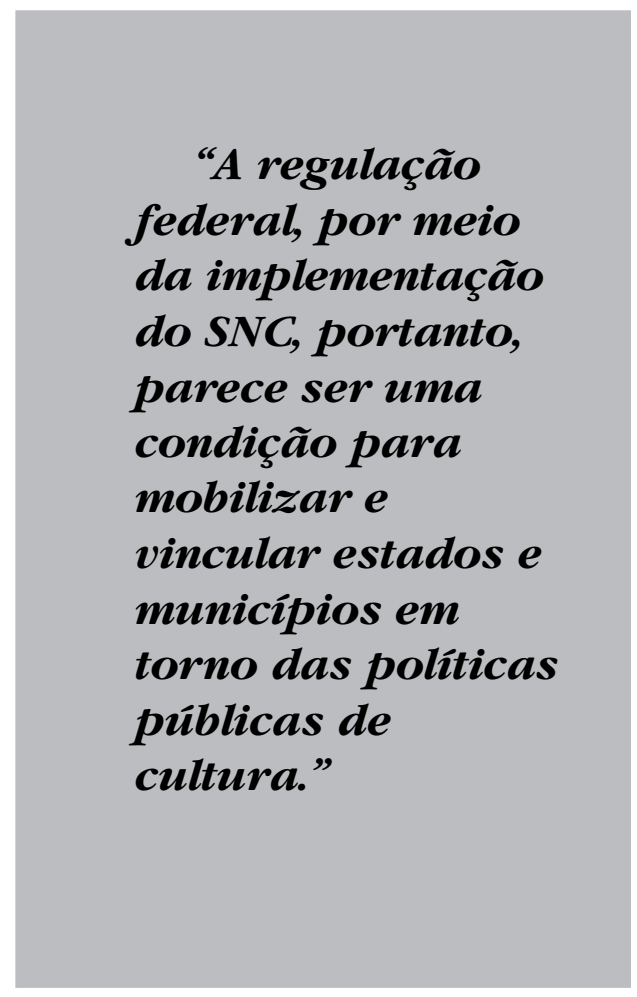

pesquisadores, no geral, consideram o SUS um grande avanço, quando comparado à situação anterior à sua criação.

Assim, conforme demonstrado por Arretche (2010), a regulação federal trouxe contribuições e melhorias, por reduzir as discrepâncias municipais na provisão de serviços públicos básicos de saúde. $\mathrm{Na}$ ausência do exercício/desempenho pela 
União de seu papel de regulamentação e de supervisão, a tendência seria "uma corrida para baixo" no gasto em saúde dos governos locais, prejudicando o atendimento à população.

\section{O Sistema Nacional de Cultura como arranjo institucional de articulação e compartilhamento interfederativo de políticas culturais}

As políticas culturais empreendidas pelo governo federal, em sua quase totali$\mathrm{dade}^{7}$, não apresentam, até o atual contexto, traços que as possam caracterizar como políticas reguladas, nos termos de Arretche (2010). São políticas de âmbito nacional, mas que em seu desenho, em geral, não preveem processos e mecanismos de descentralização de ações - e consequentemente de recursos - para estados e municípios. Pode-se afirmar que o Ministério da Cultura não tem tradição de articulação com outras esferas de governo para apoio de iniciativas públicas culturais subnacionais. Nesse sentido, não é usual encontrar nos programas e projetos federais da área intenções e diretrizes para uma atuação interfederativa. Uma exceção é o "Programa Arte Cultura e Cidadania Cultura Viva", que, num processo incremental, teve seu formato institucional alterado, passando a "descentralizar" para estados interessados no programa, como meio de potencializar suas ações e alcance. Além disso, as ações culturais federais sofrem frequentes redesenhos e constantes alterações programáticas e orçamentárias.

Até meados da década passada, as políticas culturais, de origem federal, praticamente se reduziam à política de financiamento, via incentivo fiscal. O Programa Nacional de Apoio à Cultura (Pronac) instituído pela Lei Rouanet (Lei nº 8.313/
1991) -, no seu mecanismo de implementação III - Incentivo a projetos culturais, era basicamente a política cultural nacional. $\mathrm{O}$ Pronac atendia e ainda atende essencialmente aos artistas, sejam eles das ditas "grandes artes" ou "populares".

Esse programa ainda representa o "carro-chefe" das políticas culturais oriundas do Ministério da Cultura. Entretanto, no governo do presidente Lula, com o ministro Gilberto Gil, iniciou-se um movimento - pautado no discurso de democratização da cultura e promoção da "cidadania cultural" - de construção de políticas públicas que, além de fomentar práticas culturais em sua diversidade, fossem capazes de assegurar a todos os cidadãos brasileiros o exercício dos direitos culturais, dispostos na nossa Constituição de 1988. Esse desafio converteu-se em projetos de reformulação de leis, redesenho de mecanismos institucionais, inclusive para uma atuação intergovernamental, e na elaboração de novas ações e programas.

O debate sobre o Sistema Nacional de Cultura (SNC) foi lançado pelo MINC em 2003. A ideia já estava presente na plataforma de governo do então presidenciável Luís Inácio Lula da Silva. A proposta foi amplamente discutida em vários fóruns, com a participação de representantes governamentais das três esferas, de mandatários do Poder Legislativo, de movimentos sociais e de segmentos culturais da sociedade.

O projeto do Sistema Nacional de Cultura é resultado desse processo de debates e de constituição de um novo marco legal ${ }^{8}$ para a área da cultura. Nesse sentido, os argumentos apresentados no documento Estruturação, Institucionalização e Implementação do Sistema Nacional de Cultura (MINC, 2011) alegam que se trata de uma política estruturante do campo, uma política de Estado, que se pretende mais resistente às 
alternâncias democráticas de poder e garantidora dos direitos culturais.

Em suma, os direitos culturais têm características mistas; são simultaneamente civis, políticos, econômicos e sociais; subvertem as classificações rígidas e adquirem estatuto próprio; e necessitam, para efetivar-se, da ação compartilhada de indivíduos, comunidades e Estado.

Essa constatação leva a concluir que são múltiplas e complexas as ações que envolvem a implantação de um Sistema Nacional de Cultura. Não se trata de colocar uma "camisa de força" na cultura, como pensam críticos isolados, mas de fortalecer a política pública de cultura. De fato, a criatividade humana é livre e dinâmica, como demonstra a existência mesma da História, e não cabe ao Estado dirigir seus passos. No entanto, há atribuições que o Estado, objetivamente, tem de cumprir: (1) assegurar que a liberdade de criar não sofra impedimentos; (2) garantir aos criadores as condições materiais para criar e usufruir dos benefícios resultantes das obras que produzem; (3) universalizar o acesso de todos os cidadãos aos bens da cultura; (4) proteger e promover as identidades e a diversidade cultural; e (5) estimular o intercâmbio cultural nacional e internacional (MINC, 2011, p.16).

Assim, o sistema idealizado tem dupla função; é ao mesmo tempo uma política pública nacional e um modelo de gestão compartilhada, tal como o Sistema Único de Saúde e o Sistema Único de Assistência Social. Conforme o documento, o SNC foi concebido com um arranjo institucional que possibilite articulação e pactuação das relações intergovernamentais, com instâncias de participação e controle social, de modo a viabilizar implementação de políticas culturais em todo território nacional. De acordo com a proposta, a "essência" do sistema é a coordenação e cooperação entre os entes da federação, para que se tenha economicidade, eficiência, eficácia, equidade e efetividade na aplicação dos recursos públicos.

O SNC tem como objetivo geral "Formular e implantar políticas públicas de cultura, democráticas e permanentes, pactuadas entre os entes da federação e a sociedade civil, promovendo o desenvolvimento - humano, social e econômico com pleno exercício dos direitos culturais e acesso aos bens e serviços culturais" (Minc, 2011, p. 42). É constituído pelos seguintes elementos: órgãos gestores da cultura, conselhos de política cultural, conferências de cultura, sistemas de financiamento (com fundos de fomento à cultura), planos de cultura, sistemas setoriais de cultura, comissões intergestores tripartite e bipartite, sistemas de informações e indicadores culturais e programas de formação na área da cultura. Estrutura e componentes bastante similares aos do SUS.

Sua configuração comporta a integração dos sistemas municipais, estaduais e distrital de cultura, e dos sistemas setoriais (de bibliotecas, museus, patrimônio etc.), à medida que forem criados (ou reformulados) dentro dos parâmetros previstos na proposta. Desse modo, conforme o documento do SNC, todos os sistemas de cultura (estaduais e municipais) devem seguir, balizados pelas condições e pertinência, o mesmo desenho, ou seja, ter os mesmos elementos constitutivos do sistema nacional. A adoção de um padrão de estrutura similar em todos os níveis governamentais pode 
ser explicada como estratégia para garantir a existência dos fóruns, instrumentos e canais necessários para facilitar o diálogo político e o fluxo de programas e recursos relativos às políticas de cultura. Como defesa ao questionamento da uniformização, que se estaria pondo a "cultura" numa "camisa de força", argumenta-se que o conteúdo da política pública local será construído principalmente pelas instâncias de negociação e pactuação - entre governo e sociedade - previstas no sistema municipal, em consonância com a política estadual e nacional. Essa lógica de construção das políticas culturais asseguraria a manifestação da diversidade cultural existente no território do País.

O diagrama seguinte, reproduzido do documento Estruturação, Institucionalização e Implementação do Sistema Nacional de Cultura (Minc, 2011, p. 45), pode ajudar na compreensão da arquitetura estruturada.

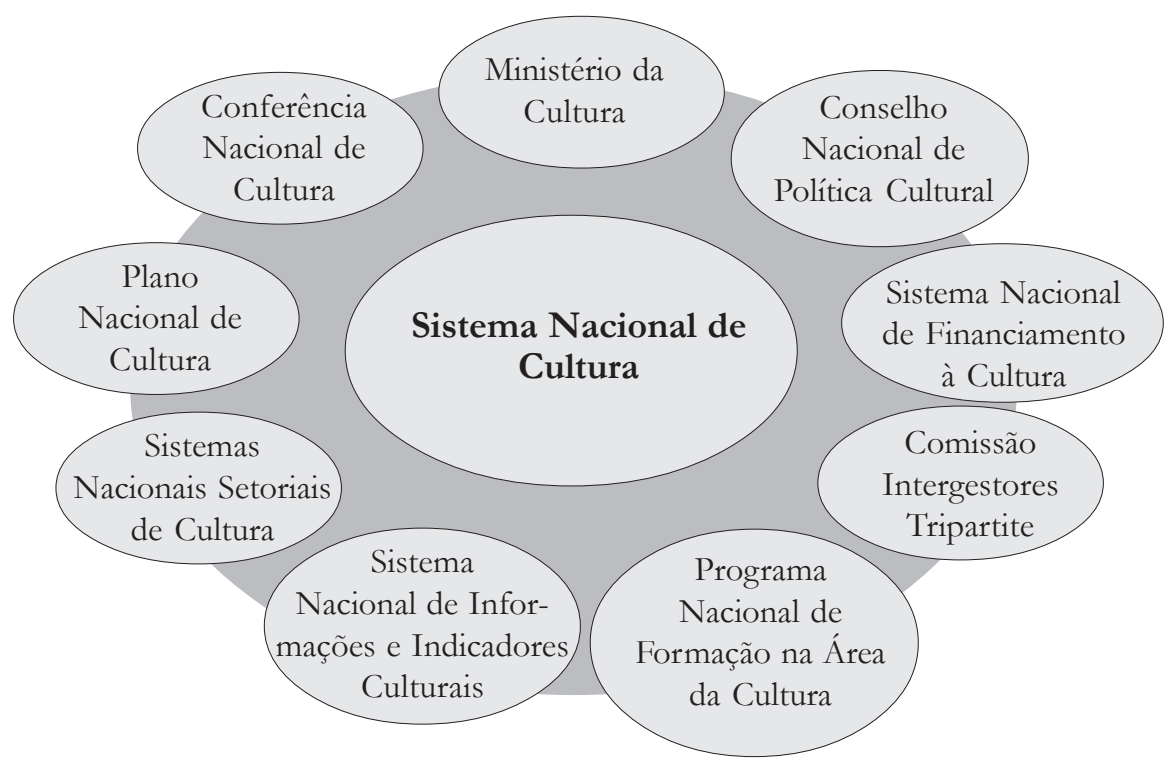

Fonte: MINC, 2011.

\section{Figura 1: Sistema Nacional de Cultura}




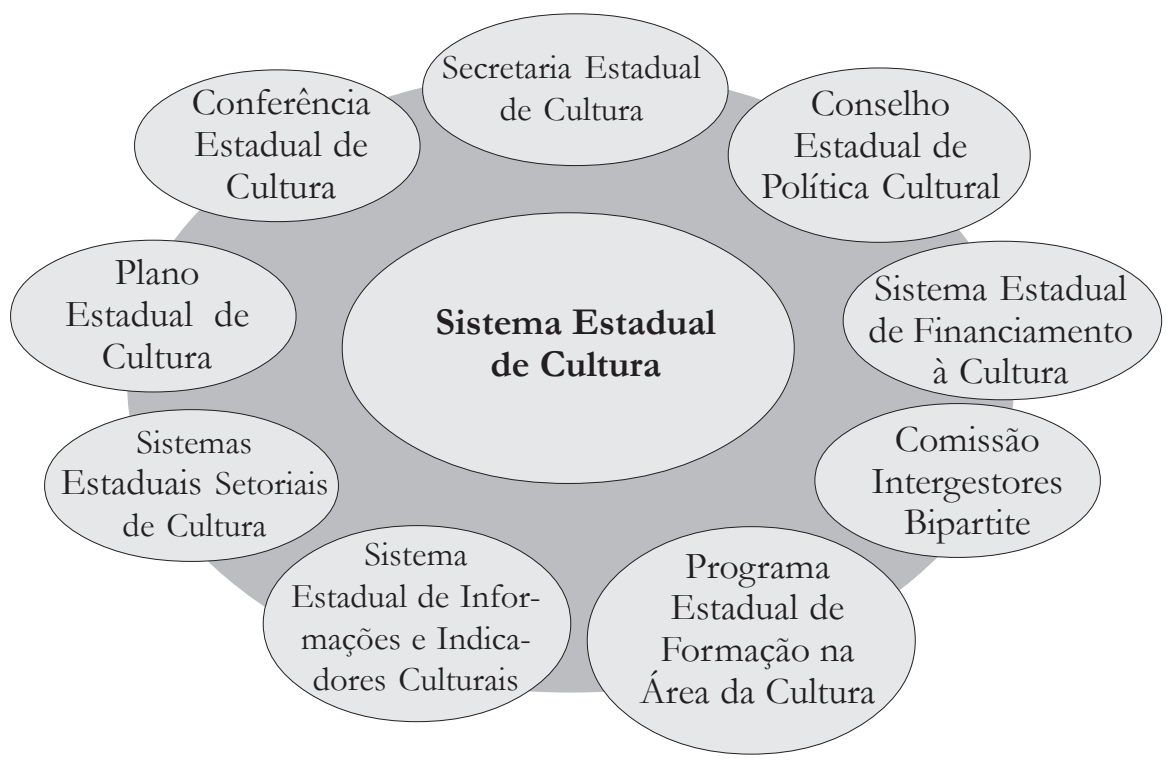

Fonte: MINC, 2011.

Figura 2: Sistema Estadual de Cultura

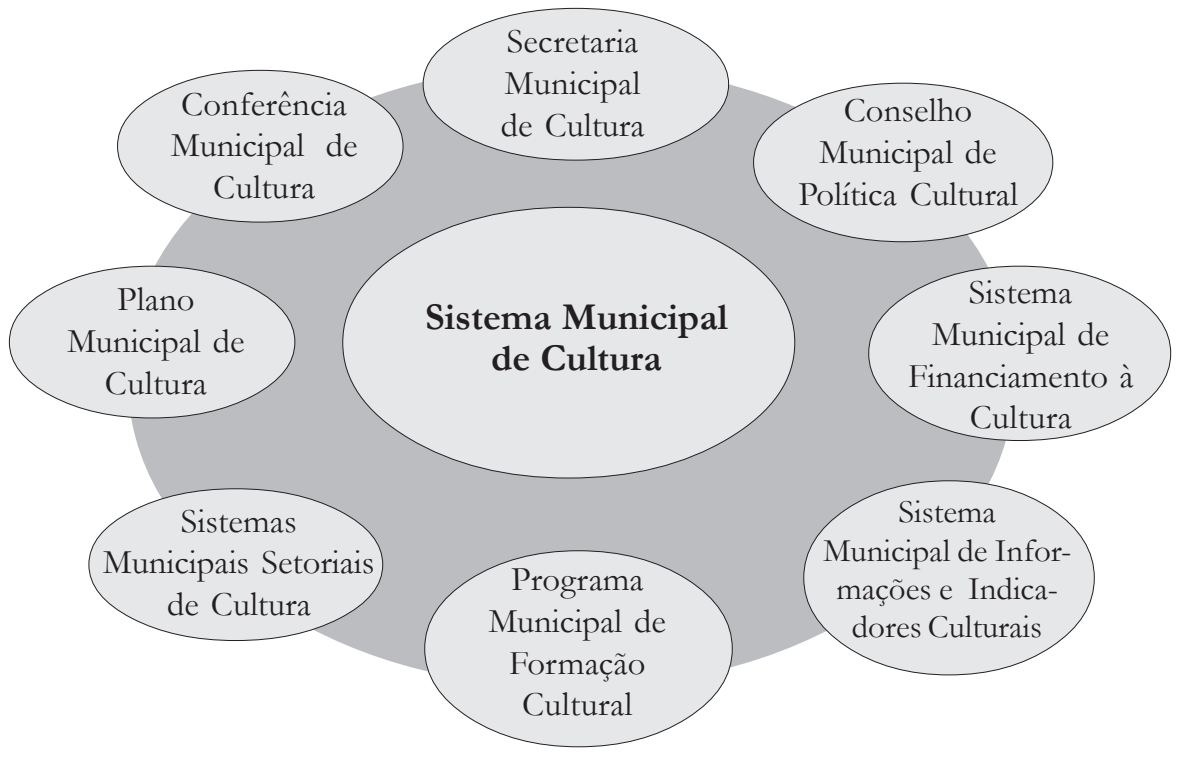

Fonte: MINC, 2011.

Figura 3: Sistema Municipal de Cultura 
Posto que uma das finalidades da política pública Sistema Nacional de Cultura é justamente articular a cooperação intergovernamental, verifica-se que seu recorte territorial é o federativo. Por isso, vai se utilizar de mecanismos de indução à constituição de sistemas distrital, estaduais e municipais, com aparato institucional que possibilite o estabelecimento de relações de colaboração entre os governos de mesma estatura jurisdicional e entre distintos níveis federativos.

Tal como no SUS, estão previstos na estrutura do SNC espaços institucionalizados de articulação, pactuação e deliberação para construção de políticas públicas de cultura, de forma compartilhada entre Estado e sociedade. As principais instâncias de participação social são as conferências de cultura e os conselhos de política cultural, nos quais devem ser negociadas e deliberadas as diretrizes das políticas públicas para o setor. Os conselhos são de caráter permanente e ambiciona-se que tenham como uma de suas principais atribuições a formulação de estratégias e diretrizes para a alocação de recursos das políticas públicas de cultura, além de ter o papel de controle da execução dessas políticas.

Dessa configuração complexa, o que interessa para esse trabalho, nesse momento, são as comissões intergestores tripartite (com representação federal, estadual e municipal) e bipartites (com representação estadual e municipal), por igualmente serem espaços de concertação e de estabelecimento de acordos, porém com a especificidade de se tratar de fóruns de pactuação interfederativa das ações governamentais, no que tange aos aspectos operacionais da gestão do sistema. Essas arenas portam a particularidade de possibilitarem o diálogo permanente intergovernamental, essencial para a tomada de compromissos politicamente negociados no âmbito do Sistema Nacional de Cultura, constituindo-se, desse modo, como um dos principais mecanismos de coordenação e cooperação federativa dessa arquitetura institucional. A ideia das comissões intergestores foi uma das grandes contribuições do SUS para a condução de um trabalho intergovernamental.

Importa também saber que a gestão e coordenação do SNC, na esfera nacional, competem ao Ministério da Cultura, e nos outros níveis de governo, às secretarias estaduais (distrital) e municipais de cultura ou equivalentes. São esses elementos institucionais combinados que pretendem permitir a regulação federal, por meio da construção das regras de funcionamento do sistema. Nesse sentido, verificam-se sinais de uma política regulada, nos termos de Arretche (2010), uma vez que a autoridade central é responsável pela formulação (em acordos negociados com a representação das unidades subnacionais) do que vai ser executado pela autoridade local, dentro dos parâmetros normatizados. Além disso, caberá ao governo federal controlar a principal fonte de financiamento e os mecanismos de coordenação intergovernamental do SNC. Fatores que afetam fortemente as decisões dos governos subnacionais, de acordo com Arretche (2010).

Observa-se, portanto, que o arranjo institucional intergovernamental projetado na proposta do SNC - à semelhança do SUS - contempla a descentralização de políticas públicas a estados e municípios, de forma regulamentada e sob a supervisão do governo federal. Esse aspecto é reforçado pelos instrumentos de gestão previstos para todos os entes federados que aderirem ao SNC: planos e orçamentos de cultura, relatórios de gestão e sistemas de informações e indicadores culturais. Os 
planos nacional, estaduais e municipais de cultura visam a estabelecer planejamentos decenais de políticas públicas que sejam convergentes ou que tenham pontos de contato potencializadores dos esforços e recursos. O planejamento orçamentário (com suas peças: Planejamento Plurianual (PPA) -, Lei de Diretrizes Orçamentárias (LDO) e Lei Orçamentária Anual - LOA) seria a "ferramenta" de tradução dos planos de cultura de modo a expressar a projeção das receitas e autorizar os limites de gastos nos programas e ações culturais propostos. Quanto aos sistemas de informações e relatórios de gestão, são instrumentos de apoio ao controle e supervisão.

Desde 2010, a adesão ao Sistema Nacional de Cultura tem sido por meio da assinatura de Acordos de Cooperação Federativa $^{9}$, nos quais o governante do município ou estado assume o compromisso, sobretudo, de criar, coordenar e desenvolver o Sistema Municipal/Estadual de Cultura, com os componentes previstos na arquitetura do sistema, especialmente o conselho de política cultural, o plano de cultura e o fundo de cultura (o "CPF", como ficou conhecido). E ao Ministério da Cultura compete, entre outras obrigações, criar condições de natureza legal, administrativa, participativa e orçamentária para o desenvolvimento do Sistema Nacional de Cultura. Além disso, compromete-se a compartilhar recursos para execução de programas, projetos e ações culturais, relativos ao SNC, bem como a apoiar os estados e municípios em outros quesitos, como na formação de gestores e agentes de cultura, na realização das conferências de cultura, e na própria criação e implementação dos sistemas subnacionais.

O processo de adesão é voluntário posto que os entes da federação têm autonomia político-administrativa, mas, assim como no SUS, os mecanismos de indução desenhados se utilizam da estratégia de explorar as relações de dependência entre os níveis governamentais, talhadas pelo modelo do federalismo brasileiro vigente. Entretanto, no caso da cultura, a pasta não conta ainda com recursos financeiros vigorosos e nem com uma estabilidade orçamentária, que lhe permita fazer dos repasses de recursos um grande trunfo para a coordenação das políticas dos entes subnacionais (GONÇALVES et alii., 2008). Pode-se inferir que é especialmente a expectativa de mudança nesse campo que tem sido a força motriz das adesões. Ou seja, há o reconhecimento de que o poder de coordenação está com a autoridade central, que é quem poderá fazer repasse de recursos para as políticas acordadas nos planos de cultura.

A proposta do SNC, nesse sentido, também postula a reformulação do Fundo Nacional de Cultura para que ele seja o principal mecanismo de financiamento das políticas públicas de cultura. Para isso, é preciso que o fundo tenha um formato que possibilite realizar transações fundo (nacional) a fundo (estaduais e municipais). Assim, está em tramitação no Congresso Nacional o Projeto de Lei no 6.722/ 2010, referente ao Programa Nacional de Fomento e Incentivo à Cultura (Procultura), que pretende corrigir as distorções identificadas na Lei Rouanet, e também dispõe sobre a montagem de um esquema de repasse de recursos do Fundo Nacional de Cultura para Estados, Distrito Federal e Municípios. Os governos estaduais e municipais terão que aportar recursos próprios aos seus respectivos fundos de cultura, de modo que esses fundos possam se tornar peças centrais do sistema de cofinanciamento das políticas públicas de cultura. 
Além disso, há a Proposta de Emenda Constitucional nº 150/2003, que tem como principal objetivo designar recursos financeiros à cultura com vinculação orçamentária. Busca-se, desse modo, criar condições para o estabelecimento de transferências regulares condicionadas ao cumprimento das regras de uso dos recursos nos programas e ações culturais definidos nos planos de cultura. Trata-se, portanto, de normas que buscam vincular o gasto de recursos financeiros públicos a políticas específicas. Nesse sentido, esse mecanismo seria mais um aparato institucional que caracterizaria o SNC como uma política regulada, uma vez que, para Arretche:

"Regras que vinculam as receitas dos governos subnacionais ao gasto em políticas específicas são um componente central das políticas federais de regulação das políticas descentralizadas. Estas limitam a autonomia decisória das unidades constituintes com relação à alocação de seus próprios recursos." (2010, p. 602).

No que diz respeito à questão que envolve o tema limitação da autoridade local na tomada de decisão sobre o gasto, o cenário atual, no qual há total autonomia alocativa dos governantes estaduais e municipais no campo das políticas culturais, é de assombrosas desigualdades inter e intraestaduais, mesmo em se tratando de direitos constitucionalizados. Como consequência, não é igual territorialmente o acesso da população a políticas públicas desse setor. Nesse sentido, a área da cultura, por não ter politicas reguladas, não é prioridade para a autoridade local na alocação de recursos e tampouco na provisão de serviços. E, como ainda não há mecanismos de atrelamento que constranjam o Poder
Executivo local a cumprir "patamares de gasto e modalidades de execução das políticas" (Arretche, 2010, p 603), os direitos culturais não estão assegurados a todos os brasileiros.

Ademais, esse modelo de gestão análogo ao SUS -, que se realiza principalmente pelo estabelecimento de relações coordenadas e cooperativas entre a União, os Estados, o Distrito Federal e os Municípios, permitiria superar os limites impostos pelos instrumentos atuais de colaboração - convênios e contratos -, simplificando as relações burocráticas interfederativas.

\section{Considerações finais}

A regulação federal é um tema polêmico que gera demasiadas tensões, pois é interpretada por muitos teóricos e atores políticos como uma grande intromissão (até mesmo intervenção) do governo federal nos assuntos das outras unidades constituintes da Federação. O que estaria em jogo, ou melhor, supostamente ameaçada seria a autonomia política dos governos subnacionais frente à autoridade central. Porém, há outras leituras possíveis, como a de que a regulação federal da descentralização de responsabilidades na condução das políticas públicas estaria, na verdade, reforçando uma lógica de fortalecimento dos governos estaduais e municipais.

Em meio a essas controvérsias, o que pode ser verificado, segundo a análise comparativa realizada por Arretche (2010) a respeito das políticas públicas descentralizadas reguladas e não reguladas, é que as políticas não reguladas - nas quais a autoridade local goza de autonomia para tomar decisões sobre a formulação e a execução das políticas - têm resultado num gasto municipal baixo ou nulo em políticas sociais. Esse comportamento-padrão 
demonstra que, sem constrangimentos exógenos aos municípios, os prefeitos não costumam eleger como prioridade a alocação de recursos nas áreas sociais, como saúde e educação, que beneficiam principalmente os mais pobres. Pode-se dizer, com base na Munic 2006, que ocorre o mesmo comportamento para a área da cultura.

A autonomia decisória da autoridade local assegura-lhe a possibilidade de discordância da política conduzida pelo governo central, ou seja, abre espaço para projetos políticos divergentes, que tendem a aumentar os patamares de desigualdade no gasto público e na provisão de serviços públicos entre os municípios. Em contraponto, a autoridade regulatória centralizada na União permite a adoção de mecanismos institucionais que produzem efeitos de convergência sobre os municípios, isto é, adesão a objetivos que visam a reduzir desigualdades interjurisdicionais, relativas à atuação estatal no campo dos serviços públicos municipais. Nesse sentido, o federalismo brasileiro, como explica Arretche (2010), combinaria duas tendências apenas aparentemente contraditórias, que seriam o papel regulatório do governo central operando no sentido da uniformidade e a autonomia dos governos locais operando no sentido da divergência de políticas. É o equilíbrio tenso entre o fator de convergência e as forças divergentes, nas relações central-local, que reduz o intervalo de discrepâncias territoriais, no que diz respeito à produção de políticas públicas, sobretudo as sociais.

Portanto, para cumprir o disposto no inciso III, art. $3^{\circ}$ da Constituição, que faz referência a um dos objetivos fundamentais da República Federativa do Brasil, "erradicar a pobreza e a marginalização e reduzir as desigualdades sociais e regionais" (grifo nosso), compete à União, por meio do governo federal, atuar na superação das desigualdades interjurisdicionais, coordenando a cooperação entre os diversos centros de governo na produção de políticas públicas, ou seja, exercendo seu papel regulatório e redistributivo.

Assim, a regulação federal no formato institucional SUS tem desempenhado o papel “de 'amarrar' subunidades independentes em torno de um dado objetivo nacional" (ARRETCHe, 2010, p. 611). O SUS desenvolveu mecanismos de enfrentamento dos gargalos federativos de modo a aprimorar a implementação de políticas públicas federativas e a viabilizar a sua gestão. Criaram-se espaços institucionalizados de negociação e pactuação, que possibilitaram a conformação de estratégias de coordenação intergovernamental. Os Pactos de Saúde, adotados a partir de 2006, são decorrência desse processo, que, sob a compreensão de que se trata de um federalismo cooperativo, como apresentado por Franzese (2010), representa uma composição de autonomia com interdependência e um compartilhamento entre governo central e governos subnacionais de compromissos políticos relacionados à política de saúde, decididos conjuntamente.

Poder-se-ia perguntar, a partir de outra perspectiva teórica, se a atual estrutura institucional do SUS para a tomada de decisões - que hoje está mais pautada pela pactuação como mecanismo de coordenação interfederativa da política de saúde, ou seja, pelo compromisso político entre os gestores, do que pela estratégia de induzir a tomada de decisões no âmbito estadual e municipal a partir de incentivos financeiros - não configuraria um processo decisório mais matricial entre os entes federados do que piramidal (centralizado na autoridade no governo central). E se esse 
entendimento não questionaria a pertinência da regulação federal tal como disposta por Arretche (2010). Entretanto, conforme Arretche (2010), a regulação federal diz respeito ao conjunto da legislação federal sobre as políticas executadas pelas unidades constituintes da federação, à autoridade para supervisionar essas políticas, e à função de redistribuição de recursos entre os entes federados, ou seja, é o governo federal quem controla o financiamento e os mecanismos de coordenação intergovernamental. Esse aparato institucional exerce constrangimento sobre as decisões dos governos subnacionais.

A leitura acerca do padrão de gasto dos governos locais para políticas reguladas e não reguladas pode ser estendida, tomando como base a Munic (2006) e outros levantamentos, para as políticas culturais. Nesse sentido, em razão de não haver, no campo das políticas públicas de cultura, mecanismos institucionais que induzam e regulem a execução descentralizada, o painel é de enorme desigualdade no território nacional, com centralização de recursos e ações no Sudeste e grande fragmentação de esforços e iniciativas. Juntam-se a esse cenário desarticulação e ausência de cooperação entre os entes federados nas ações governamentais do campo cultural.

Arranjos institucionais como o proposto - com estratégias e instrumentos interfederativos de planejamento, regulação e cofinanciamento - podem ter efeitos positivos na performance da ação estatal, na promoção ou indução de políticas culturais, tal como demonstrado por Arretche (2010) nas áreas de saúde e educação.

A regulação federal, por meio da implementação do SNC, portanto, parece ser uma condição para mobilizar e vincular estados e municípios em torno das políticas públicas de cultura. Ademais, o mecanismo de transferências condicionadas de recursos "fundo a fundo", central para o cumprimento pela União do papel de redistribuição de receitas entre as unidades subnacionais, tem previsão de funcionar no SNC, tal como no SUS e no SUAS, com base em regras transparentes e, por isso, não sujeito a barganhas políticas. Outro aspecto a destacar sobre a proposta de política regulada SNC é o papel do sistema na redução das desigualdades financeiras, técnicas e de gestão dos governos subnacionais, para que tenham capacidade de implementar políticas públicas de cultura. Uma estratégia projetada é a de fortalecimento institucional desses governos por meio de programas de formação e de capacitação nessa área.

De qualquer forma, nas políticas públicas reguladas, ou seja, em que a União compromete os governos subnacionais com políticas específicas, há a autonomia da autoridade local sobre a execução das políticas, assim como sobre a possibilidade da discordância e encerramento da cooperação. Ressalta-se que a adesão ao SNC é uma escolha (induzida, é claro, principalmente pela promessa de incentivos financeiros) do governante da unidade federada. Além disso, o projeto do SNC prevê instâncias apropriadas para negociações federativas referentes à implementação e execução das políticas culturais, que podem se configurar em espaços de resolução de tensões, por meio da colaboração e atuação conjunta. Em tese, com os fóruns tripartite de negociação, estados e municípios estão incluídos no processo de compartilhamento decisório da Federação. Trata-se, dessa forma, de uma combinação entre regulação federal (regulamentação e supervisão) e autonomia local (porém pautada por legislação federal).

O Sistema Nacional de Cultura pode, portanto, tornar viável a pactuação - no 
campo da cultura - da distribuição de competências e atribuições pelos três níveis de governo. A aposta é a de que a concertação advinda do pacto federativo permitiria a integração das políticas culturais, que podem evitar ações atomizadas e superpostas, causadoras de desperdícios de vários recursos. Considerando todos esses aspectos, o SNC também pode ser visto como uma política estratégica para o desenvolvimento local, articulando-o com o regional e com o nacional.

A atuação federal, via SNC, no que tange à participação cidadã na gestão da "coisa pública", pretende também instigar o protagonismo da população do "lugar" para a definição de suas políticas culturais. Por isso, o município (e/ou estado) deve, ao criar o seu sistema, "reproduzir" o desenho do SNC (dentro da pertinência), principalmente no que se refere às instâncias de articulação, pactuação e deliberação com a sociedade civil. O discurso é que, desse modo, estar-se-á criando condições para dinamizar a diversidade cultural, que é um dos princípios do Sistema Nacional de Cultura.

Outra aposta, que diz respeito ao SNC como política garantidora de acesso (do exercício dos direitos culturais), por meio da indução dos governantes locais na provisão de políticas públicas, é possibilitar o desenvolvimento de potencialidades culturais em todo o Brasil, ou seja, investir no estímulo a interações sócio-culturais, compreendendo que o contato com o "diferente" é provocador/instigador de questionamentos e de inquietações. E, por isso, tem potencial de alargamento do horizonte de possibilidades dos modos de criar, fazer e viver dos diferentes grupos formadores da sociedade brasileira.

Assim, pode-se chegar à conclusão de que a proposta do $\mathrm{SNC}$, por todos os seus componentes e instrumentos, enquadra-se na conceituação de política regulada, tal como o SUS. Com isso, vislumbra-se a possibilidade de equalizar a oferta de ações que possam garantir os direitos culturais, constituindo-se em uma forma de reverter as desigualdades inter e intraestaduais no que tange à promoção de políticas culturais e ao seu acesso.

Por fim, arranjos institucionais intergovernamentais que reforcem os papéis regulatório e redistributivo do governo central, conforme Arretche (2010), parecem ser mecanismos necessários para obter cooperação entre jurisdições. Nesse sentido, o Sistema Nacional de Cultura é apontado como essencial para fortalecer a função do Estado na institucionalização das políticas públicas culturais. Portanto, a regulação federal pode ser indispensável para induzir a universalização das políticas públicas de cultura e, dessa forma, garantir a nominada "cidadania cultural".

(Artigo recebido em janeiro de 2013. Versão final em março de 2013). 


\section{Notas}

${ }^{1}$ Este artigo é uma versão revisada e ampliada do trabalho "Relações Federativas e Arranjos Institucionais Intergovernamentais: o Sistema Nacional de Cultura” apresentado (e publicado nos Anais) no VIII ENECULT - Encontro de Estudos Multidisciplinares em Cultura, promovido pelo Centro de Estudos Multidisciplinares em Cultura (Cult), pelo Programa Multidisciplinar de Pós-Graduação em Cultura e Sociedade-Pós-Cultura, pela Faculdade de Comunicação e pelo Instituto de Humanidades, Artes e Ciências Professor Milton Santos (IHAC), da Universidade Federal da Bahia, realizado de 8 a 10 de agosto de 2012.

${ }^{2}$ Segundo Franzese (2010), a teoria do federalismo cooperativo, elaborada por Morton Grodzins (1966) e Daniel Elazar (1962), tem sua origem na ideia de federalismo como pacto, e foi apresentada como uma alternativa à abordagem norte-americana do federalismo dual (separação absoluta de competências), posto que assevera a existência de uma indispensável interação entre as esferas de governo na estrutura federativa, ou seja, “(...) o federalismo não significa apenas a afirmação de autonomia entre os entes, mas uma combinação de autonomia (self rule) com interdependência (shared rule)". (Franzese, 2010:21-22).

${ }^{3}$ A Emenda Constitucional no 71, promulgada no dia 29 de novembro de 2012, institui o Sistema Nacional de Cultura. Foi apresentada pelo deputado Paulo Pimenta (PT-RS) em 2005, como Proposta de Emenda Constitucional. A PEC no 416/2005 foi aprovada nos dois turnos da Câmara Federal, no primeiro semestre de 2012, na forma do substitutivo da comissão especial, de relatoria do deputado Paulo Rubem Santiago (PDT-PE), que incorporou em seu texto a configuração institucional presente no documento do Ministério da Cultura Estruturação, Institucionalização e Implementação do Sistema Nacional de Cultura. No Senado Federal, já como Proposta de Emenda Constitucional n $34 / 2012$, teve como relatora a então senadora Marta Suplicy, que se empenhou para que sua aprovação ocorresse em tempo recorde.

${ }^{4}$ A respeito do debate acerca dos direitos culturais dos cidadãos brasileiros presentes na Constituição de 1988, ver Silva (2001), Cunha Filho (2000), Cunha Filho (2011), Mata Machado (2007), Mata Machado (2011).

${ }^{5}$ Apesar de 57,9\% das administrações municipais terem respondido - à pesquisa Munic (2006) - positivamente acerca da existência de política cultural municipal, esse número deve ser relativizado. Calabre (2009) pondera que é necessário pesquisar e analisar detalhadamente com que conceitos de política cultural atuam as gestões municipais, sob o argumento de que, quando se examina os outros dados relacionados, verifica-se percentual alto de ausência de estrutura específica para a gestão municipal na área da cultura. Situação que inviabilizaria a implementação de políticas para o setor. Por isso, para Calabre (2009), haveria uma confusão conceitual, na qual os gestores estariam considerando como política cultural um somatório de ações implementadas de maneira dispersa, não planejada, sem relação entre si e de alcance limitado.

${ }^{6}$ O Pacto pela Saúde foi publicado na Portaria do Ministério da Saúde GM/MS no399, de 22 de fevereiro de 2006. É mais uma forma de consolidação do SUS por meio de um conjunto de reformas institucionais pactuado entre as três esferas de gestão (União, Estados e Municípios), em que a implementação do Pacto pela Saúde ocorre pela adesão de Municípios, Estados e União ao Termo de Compromisso de Gestão (TCG), que substitui os processos anteriores de habilitação e estabelece metas e compromissos para cada ente da Federação, e que deve ser renovado anualmente (conforme informação na página do Ministério da Saúde http://portal. saude.gov.br/portal/saude/ profissional/ area.cfm?id_area=1021, acesso em 11 de janeiro de 2013). 
${ }^{7}$ Caberia uma análise detalhada das políticas voltadas ao patrimônio, aos museus e às bibliotecas públicas para melhor identificação; porém, esses setores não são objeto deste estudo. Entretanto, suas políticas possuem arranjos sistêmicos, que foram desenvolvidos ou fortalecidos institucionalmente a partir da metade da década passada, isto é, dentro do contexto de reestruturação das políticas culturais federais.

${ }^{8}$ Há ainda: o Plano Nacional de Cultura (Lei no 12.343/2010); o Programa Nacional de Fomento e Incentivo à Cultura (ProCultura) - Projeto de Lei no 6.722/2010 -, que inclui o redesenho institucional do Fundo Nacional de Cultura; o projeto de vinculação de recursos para a cultura (Proposta de Emenda Parlamentar - PEC no 150/2003); a inserção da cultura como direito social no art. 6o da Constituição (PEC no 49/2001); a proposta de revisão da Lei de Direito Autoral; entre outros projetos.

${ }^{9}$ Até 7 de janeiro de 2013, foram realizados acordos de cooperação federativa com 23 estados da Federação (incluindo o Distrito Federal), o que representa 85,2\% do universo, e com 1.411 municípios, $25,4 \%$ dos 5.564 entes federados municipais.

\section{Referências bibliográficas}

ABrucio, Fernando L. A coordenação federativa no Brasil: a experiência do período FHC e os desafios do Governo Lula. Revista de Sociologia e Política, no 24, p. 41-67, junho 2005.

Almeida, Maria Hermínia T. de. Recentralizando a federação. Revista de Sociologia e Politica. $\mathrm{n}^{\mathrm{O}} 24$, p. 29-40, junho 2005.

Arretche, Marta. Relações Federativas nas Políticas Sociais. Educ. Soc., Campinas, v. 23, no 80, , p. 25-48, setembro/2002. Disponível em http://www.cedes.unicamp.br.

. Financiamento federal e gestão local de políticas sociais: o difícil equilíbrio entre regulação, responsabilidade e autonomia. Ciência e Saúde Coletiva, v. 8, no 2, p. 331-345, 2003.

. Federalismo e Políticas Sociais no Brasil: problemas de coordenação e autonomia. São Paulo em Perspectiva, São Paulo, v. 18, no 2, p. 17-26, 2004.

. Quem Taxa e Quem Gasta: a barganha federativa na federação brasileira. Revista de Sociologia Politica, Curitiba, 24, p. 69-85, jun. 2005.

. Federalismo e Igualdade Territorial: Uma Contradição em Termos? Revista de Ciências Sociais, Rio de Janeiro, v. 53, p. 587-620, 2010.

Brasil. Constituição (1988). Constituição da República Federativa do Brasil. Promulgada em 5 de outubro de 1988. São Paulo: Editora Atlas S.A., 2006.

. Constituição da República Federativa do Brasil de 1988. Disponível em http:/ /www.planalto.gov.br/ccivil_03/constituicao/ConstituicaoCompilado.htm.

Bucci, Maria Paula Dallari. O conceito de política pública em direito in: BUCCI, Maria Paula Dallari. Políticas Públicas: reflexões sobre o conceito jurídico. São Paulo: Saraiva, 2006.

Calabre, Lia. Gestão Cultural Municipal na Contemporaneidade. In: Calabre, Lia (org.). Políticas Culturais: reflexões e ações. São Paulo: Itaú Cultural; Rio de Janeiro: Fundação Casa de Rui Barbosa, 2009. 
Políticas Culturais no Brasil: História e Contemporaneidade. Coleção Textos Nômades nº 2. Fortaleza: Banco do Nordeste do Brasil, 2010.

Cunha Filho, Francisco Humberto. Direitos Culturais como Direitos Fundamentais no Ordenamento Jurídico Brasileiro. 1. ed. Brasília: Brasília Jurídica - DF, 2000.

. Federalismo Cultural e Sistema Nacional de Cultura. Fortaleza: Editora UFC, 2010.

. Direitos Culturais no Brasil. Revista Observatório Itaú Cultural, v. 11, p.

115-126, 2011.

Franzese, Cibele; Abrucio, Fernando L. A combinação entre federalismo e políticas públicas no Brasil pós-1988: os resultados nas áreas de saúde, assistência social e educação. Caderno ELAPP - Reflexões para Ibero- América: Avaliação de Programas Sociais. Brasília: ENAP, p. 25-42, 2009.

Franzese, Cibele. Federalismo Cooperativo no Brasil: da Constituição de 1988 aos Sistemas de Políticas Públicas. 2010. 210 f. Tese (Doutorado em Administração Pública e Governo) Escola de Administração de Empresas de São Paulo, Fundação Getulio Vargas. São Paulo. Gonçalves, Renata da R.; Lotta, Gabriela S.; Bitelman, Marina F. A Coordenação Federativa de Políticas Públicas Duas Décadas Após a Constituição Federal de 1988. ENAPG, 2008.

Guerreiro, Jória Viana; Branco, Maria Alice Fernandes. Dos pactos políticos à política dos pactos na saúde. Ciênc. saúde coletiva, Rio de Janeiro, v. 16, n. 3, Mar. 2011. Disponível em <http://www.scielo.br/scielo.php?script=sci_arttext\&pid=S141381232011000300006\&lng=en\&nrm=iso > . acesso em 16 nov. 2012. http://dx.doi.org/ 10.1590/S1413-81232011000300006.

Instituto Brasileiro de Geografia e Estatística - IBGE. Pesquisa de Informacõos Básicas Municipais. Perfil dos Municípios Brasileiros 2006 (Munic). Suplemento de Cultura. Rio de Janeiro: IBGE, 2007.

Instituto de Pesquisa Econômica Aplicada - Ipea. Políticas Sociais - acompanhamento e análise $n^{\circ}$ 16, 129-154, nov. 2008.

LiMA, Luciana Dias de et al . Descentralização e regionalização: dinâmica e condicionantes da implantação do Pacto pela Saúde no Brasil. Ciênc. saúde coletiva, Rio de Janeiro, v. 17, n. 7, jul. 2012. Disponível em $<$ http://www.scielo.br/scielo.php?script=sci_arttext\& pid=S141381232012000700030\&lng=pt\&nrm=iso > . acesso em 23 out. 2012. http://dx.doi.org/ 10.1590/S1413-81232012000700030.

Mata Machado, Bernardo Novais da. Direitos Humanos e Direitos Culturais. 2007. Disponível em < http://www.direitoecultura.com.br/wp-content/uploads/Direitos-Humanose-Direitos-Culturais-Bernardo-Novais-da-Mata-Machado.pdf $>$. acesso em 6 de novembro de 2012.

- Os direitos culturais na Constituição brasileira: uma análise conceitual e política. In: Calabre, Lia (org.). Políticas culturais: teoria e práxis. São Paulo: Itaú Cultural; Rio de Janeiro: Fundação Casa de Rui Barbosa, 2011.

Mendes, Constantino Cronemberger. O Federalismo no Brasil: pesquisas, estudos e reflexões do IPEA. Boletim de Análise Político-Institucional. Instituto de Pesquisa Econômica Aplicada. - n.1, 55-58. Brasília: Ipea, 2011. 
Ministério da Cultura. 1 Conferência Nacional de Cultura / 2005-2006: Estado e Sociedade Construindo Políticas Públicas de Cultura. Brasilia: Ministério da Cultura, 2006a. Oficinas do Sistema Nacional de Cultura. Brasília: Ministério da Cultura, 2006b. . Politica Cultural no Brasil, 2002-2006: acompanhamento e análise. Frederico A. Barbosa da Silva, autor. Brasília: Ministério da Cultura, 2007.

. Plano Nacional de Cultura: Diretrizes Gerais.2 ${ }^{\mathrm{a}}$ Ed.. Brasília: Ministério da Cultura, 2008.

Brasília, 2010.

"Conferindo os Conformes": Resultados da II Conferência Nacional de Cultura. . Estruturação, Institucionalização e Implementação do Sistema Nacional de Cultura. Conselho Nacional de Política Cultural. Secretaria de Articulação Institucional - SAI. Coordenação Geral de Relações Federativas e Sociedade.. Dezembro, 2011.

Ministério da Cultura; Fundação Nacional de Artes (Funarte). Cultura em Números Anuário de Estatísticas Culturais 2009. Brasilia: Minc, 2009.

Ministério da JustiçA. Secretaria de Assuntos Legislativos (SAL). Série Pensando o Direito - Federalismo - n⿳0 13/2009 - versão integral. Universidade Presbiteriana Mackenzie. Faculdade de Direito. TAVARES, André Ramos et al (Coord. Acad.). Brasília: Ministério da Justiça, 2009, 145 p.

Ministério da SAÚde. $A B C$ do SUS: doutrinas e princípios. Brasília: Ministério da Saúde, 1990.

- Descentralização das ações e serviços de saúde: a ousadia de cumprir e fazer cumprir a Lei. NOB 01/93. Brasília: Ministério da Saúde; 1993.

Ministério do Desenvolvimento Social e Combate À Fome. Politica Nacional de Assistência Social: PNAS/2004 - Norma Operacional Básica: NOB/SUAS. Brasilia: MDS, 2004.

Obinger, Herbert, Leibfried, Stephan e Castles, Francis G. (eds.). Federalism and the Welfare State. New World and European Experiences. Cambridge: Cambridge University Press, 2005.

PAIM, Jairnilson Silva. TeIXEIRA, Carmen Fontes. Configuração institucional e gestão do Sistema Único de Saúde: problemas e desafios. Ciência \& Saúde Coletiva, 12(Sup), p. 1819-1829, 2007.

RAZIN, Eran. Introduction: Deconcentration of Economic Activities Within Metropolitan Regions: A Qualitative Framework for Cross-national Comparison. In RAZIN, Eran et alii (eds.). Employment Deconcentration in European Metropolitan Areas. Toronto: Springer, 2007. p. 1-28.

Silva, José Afonso da. Ordenação Constitucional da Cultura. São Paulo: Malheiros Editores, 2001.

SelLers, Jefferey M. e Lidström, Anders. Decentralization, Local Government, and the Welfare State. Governance, vol. 20, no 4, p.609-632, 2007.

SouzA, Celina. Federalismo, Desenho Constitucional e Instituições Federativas no Brasil pós-1988. Revista de Sociologia Politica, Curitiba, 24, p. 105-121, jun. 2005.

Trevisan Ln, JunQueIRA LAP. Construindo o 'pacto de gestão' do SUS: da descentralização tutelada à gestão em rede. Revista Ciência e Saúde Coletiva,123(4), p. 893-902, 2007. 
Zimbrão DA SILVA, Adélia C. SUS: avanços e obstáculos no processo de descentralização e coordenação intergovernamental. Revista do Serviço Público, Brasília: ENAP, 55(4), p. 67-70, 2004.

As Relações Federativas e o Sistema Único de Assistência Social, 2006, ENAP, mimeo.

. Sistemas nacionais na área de gestão pública: a construção do Sistema Nacional de Cultura. In: Anais do II Congresso Consad de Gestão Pública, 6, 7 e 8 de maio de 2009, Brasília, (http://www.consad.org.br/sites/1500/1504/00001338.pdf). 


\section{Resumo - Resumen - Abstract}

Políticas públicas e relações federativas: o Sistema Nacional de Cultura como arranjo institucional de coordenação e cooperação intergovernamental

Adélia Zimbrão

Este texto tem o objetivo de analisar o projeto do Sistema Nacional de Cultura balizado por questões referentes às relações federativas e à descentralização de políticas públicas. Para esse intento, toma como base a conceituação política regulada e não regulada, elaborada por Marta Arretche para distinguir relações intergovernamentais central-local atinentes à autoridade sobre a formulação e sobre a execução de políticas públicas. Examina-se a configuração institucional de articulação e compartilhamento interfederativo de políticas públicas de cultura presente na proposta dessa política cultural, tendo como referência o Sistema Único de Saúde. Arranjos com mecanismos institucionais que induzam e regulem a execução descentralizada, como o proposto no Sistema Nacional de Cultura, parecem ser uma condição para mobilizar e vincular estados e municípios em torno das políticas públicas de cultura. A aposta é de que espaços institucionalizados de negociação e pactuação podem proporcionar melhorias no diálogo e na cooperação entre os entes federados, para o desenvolvimento de ações governamentais na área cultural.

Palavras-chave: Políticas públicas de cultura; Sistema Nacional de Cultura; relações federativas

Relaciones Federativas y Política Pública: Sistema Nacional de Cultura como mecanismo institucional de coordinación y cooperación intergubernamental

Adélia Zimbrão

Este texto tiene como objetivo analizar el Proyecto del Sistema Nacional de Cultura demarcado por cuestiones relativas a relaciones federales y la descentralización de las políticas públicas. Para esto, se basa en los conceptos de política regulado y no regulado, elaborados por Marta Arretche para distinguir relaciones centro-localidades intergubernamentales relacionadas con la autoridad en la formulación y la implementación de políticas públicas. Examina la configuración institucional de articulación interfederativo y el intercambio de las políticas culturales públicas en el diseño de esta política cultural, teniendo como referencia el Sistema Nacional de Salud. Configuraciones con mecanismos institucionales que inducen y regulan la ejecución descentralizada, como se propone en el Proyecto Sistema Nacional de Cultura, parece ser una condición para movilizar y unir los estados y municipios alrededor de las políticas públicas de la cultura. La apuesta es que los espacios institucionalizados de negociación y el acuerdo puedan proporcionar mejoras en el diálogo y en la cooperación entre las entidades federativas, para el desarrollo de las acciones gubernamentales en el área cultural.

Palabras clave: Políticas públicas de cultura; Sistema Nacional de Cultura; Relaciones Federativas

Federative Relations and Public Policy: National Culture System as institutional arrangement for coordination and intergovernmental cooperation Adélia Zimbrão

This article analyzes the National Culture System project focusing on questions on federative relations and decentralization of public policies, in particular on the relationships between central, state and local administrations, as they deal with the elaboration and implementation of 
public policies. For this purpose, we rely on the concepts of regulated and unregulated policies formulated by Marta Arretche. In examining such processes and mechanisms, comparisons with its analogue, the National Health System appears to be relevant. Institutional arrangements that induce and regulate decentralized execution, as proposed in the National Culture System, facilitates the mobilization of the public actors involved, strengthening the ties between them around the public cultural policies. The main idea is that the creation of institutionalized spaces of negotiation and agreement may bring dialogue and cooperation among federal entities for the development of governmental actions in the cultural area.

Keywords: Cultural Public Policies; National Culture System; Federative Relations

Adélia Cristina Zimbrão da Silva

Graduada em Psicologia (UERJ), especialista (lato sensu) em Sociologia Urbana (UERJ) e Mestre em Administração Pública (EBAP/FGV). Integra a carreira de Especialista em Políticas Públicas e Gestão Governamental do Ministério do Planejamento, Orçamento e Gestão, em exercício na Fundação Casa de Rui Barbosa. Contato: adeliazimbrao@rb.gov.br 